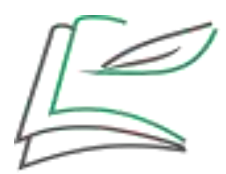

ISSN (impresso) 1519-5392

Entretextos

ISSN (digital) 2764-0809

DOI: $10.5433 / 1519-5392.2021 v 21$ n2.p.78

\title{
BNCC de Língua Portuguesa: um olhar comparativo entre as fases do Ensino Fundamental e do Ensino Médio
}

\author{
Portuguese teaching National Common Curricular Core: a \\ comparative view between the phases of elementary and high \\ school
}

\section{La Base Nacional Comum Curricular de lengua portuguesa: una mirada comparativa entre las fases de enseñanza primaria $y$ secundaria}

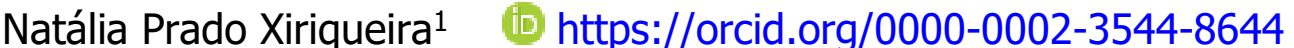 \\ Eliana Merlin Deganutti de Barros ${ }^{2}$ (iD https://orcid.org/0000-0001-9241-9375
}

\begin{abstract}
RESUMO: A Base Nacional Comum Curricular (BNCC) é um documento prescritivo que norteia processos de ensino e aprendizagem quanto aos conteúdos e habilidades tidas como essenciais aos alunos em todas as etapas e modalidades da Educação Básica. Diante de sua importância, essa pesquisa visa confrontar seções do documento que tratam da área da Linguagem e do componente Língua Portuguesa na fase final do Ensino Fundamental e no Ensino Médio. A interpretação dos dados, com apoio de uma análise documental de conteúdo, busca respaldo na noção de gêneros textuais/discursivos como objetos do letramento escolar e em conceitos basilares para a compreensão do texto da BNCC, como práticas de linguagem, competência e habilidade e campos da atuação. Os resultados apontam, entre outros aspectos, que a BNCC do Ensino Médio busca, em relação ao Ensino Fundamental, aprofundar aspectos políticos, sociais e culturais relacionados aos gêneros de referência social para o ensino, a partir de uma abordagem mais crítica e autônoma, dando ênfase à inserção de gêneros próprios dos letramentos digitais contemporâneos.
\end{abstract}

PALAVRAS-CHAVE: BNCC. Gêneros textuais. Ensino da Língua Portuguesa.

ABSTRACT: The Brazilian National Common Curricular Base (BNCC) is a prescriptive document that guides the teaching and learning processes for the contents and skills taken as essential to the students of all the steps and modalities of basic education. Given its importance, this research aims to confront sections of the document which approach the

${ }^{1}$ Graduada em Letras Português-Inglês (UENP). Membro do grupo de pesquisa DIALE (CNPq/UENP). E-mail: nataliapradoveg@gmail.com

2Doutorado em Estudos da Linguagem (UEL). Professora associada da Universidade Estadual do Norte do Paraná (UENP). E-mail: elianamerlin@uenp.edu.br 
BNCC de Língua Portuguesa: um olhar comparativo entre as fases do Ensino Fundamental e do Ensino Médio

Language area and the Portuguese Language component in the final phase of the Elementary and High School. The data interpretation, supported by documental analysis content, seeks assist in the notion of discursive/textual genres as objects of school literacies and in basic concepts for understanding the BNCC text, such as language practices, competence and skills in fields of action. The results show, among other aspects, that the High School BNCC seeks, in relation to the Elementary School, to deepen political, social, and cultural aspects allied to the social reference genres for teaching, from a more critical and autonomous approach, emphasizing the insertion of genres typical of contemporary digital literacies.

KEYWORDS: BNCC. Text Genres. Portuguese Language Teaching.

RESUMEN: La Base Curricular Común Brasileña (BNCC) es un documento normativo que orienta los procesos de enseñanza y aprendizaje sobre los contenidos y competencias que se consideran esenciales para los estudiantes en todas las etapas y modalidades de la Educación Básica. Dada su importancia, esta investigación tiene como objetivo confrontar apartados del documento que abordan el área de Lengua y el componente de Lengua Portuguesa en la fase final de Enseñanza Fundamental. La interpretación de los datos, con el apoyo de un análisis de contenido documental, busca apoyo en la noción de géneros textuales / discursivos como objetos de letramiento escolar y en conceptos básicos para la comprensión del texto BNCC, tales como prácticas del lenguaje, competencias y habilidades y campos del actuación. Los resultados muestran, entre otros aspectos, que el BNCC de Enseñanza Media busca, en relación a Enseñanza Fundamental, profundizar aspectos políticos, sociales y culturales relacionados con los géneros de referencia social para el enseñanza, desde un enfoque más crítico y autónomo, dando énfasis en la inserción de géneros propios de letramientos digitales contemporáneas.

PALABRAS-CLAVE: BNCC. géneros textuales. enseñanza de Lengua Portuguesa.

\section{Introdução}

A Base Nacional Comum Curricular (BNCC) (BRASIL, 2018) é um documento de caráter normativo que define as diretrizes para as aprendizagens essenciais que todos os alunos devem desenvolver ao longo das etapas e modalidades da Educação Básica. 0 documento surge no bojo da necessidade de atualizar, entre outras coisas, diretrizes anteriores que ainda não contemplavam em sua integridade novas demandas sociais quanto ao uso das Tecnologias Digitais da Informação e Comunicação (doravante TDIC).

Os rápidos avanços tecnológicos dos últimos anos criaram e ressignificaram novas práticas sociais, o que indica que o ensino de Língua Portuguesa está constantemente em face de desafios relativos à produção e leitura de textos de diferentes esferas, práticas e semioses. Muito embora os Parâmetros Curriculares Nacionais (PCN) (BRASIL, 1998) já contemplassem a perspectiva das práticas sociais e dos gêneros textuais/discursivos no ensino da Língua Portuguesa, a BNCC (BRASIL, 2018), na área de Linguagens e no 
componente Língua Portuguesa, procura enfatizar a perspectiva social do uso língua e sua articulação intrínseca com outras linguagens, estabelecendo relação entre o ensino e o despertar da criticidade em práticas sociais multissemióticas.

Por ser um documento oficial que deverá nortear o ensino no país, acreditamos ser de suma importância que os professores e formadores de professores conheçam e compreendam os princípios que fundamentam esse documento. A justificativa maior desta pesquisa vem, pois, da relevância da compreensão do documento da BNCC (BRASIL, 2018) para o desenvolvimento das práticas de ensino na Educação Básica, tanto para professores quanto para formadores de professores.

Dessa forma, a importância da presente pesquisa se faz tanto no âmbito escolar básico quanto no da universidade (Licenciaturas), pois a sua implementação deverá incorrer na reavaliação de diversas diretrizes: Diretrizes Estaduais e Municipais de Ensino, Projetos Pedagógicos das Escolas da Educação Básica e também dos Cursos de Licenciaturas. Acreditamos, assim, que é de fundamental importância que um profissional da área do ensino conheça e compreenda os fundamentos do principal documento na atualidade que deverá nortear as ações didáticas em sala de aula.

Nesse contexto, a presente pesquisa visa cotejar textos da BNCC (BRASIL, 2018) relacionados à área de Linguagens e ao componente Língua Portuguesa das etapas do Ensino Fundamental (EF), Anos Finais e do Ensino Médio (EM), no que diz respeito ao ensino da língua, dando destaque, sobretudo, à abordagem dos gêneros textuais/discursivos pelo documento, uma vez que esses vêm sendo um dos pontos focais no âmbito dos estudos sobre a didatização da língua no período de escolarização.

Como metodologia, a pesquisa tem cunho exploratório, pautando-se na análise documental de conteúdo, a partir de Gil (2014, p. 27), que entende que "pesquisas dessa natureza tem como principal finalidade desenvolver, esclarecer e modificar conceitos e ideias, tendo em vista a formulação de problemas mais precisos ou hipóteses pesquisáveis para estudos posteriores". O objeto da análise são, pois, textos que compõem a BNCC (BRASIL, 2018), relacionados à área de Linguagens e ao componente Língua Portuguesa nos níveis do EF (Anos Finais) e do EM.

\section{Gêneros textuais/discursivos e sua inserção no letramento escolar}


BNCC de Língua Portuguesa: um olhar comparativo entre as fases do Ensino Fundamental e do Ensino Médio

Neste estudo, apoiando-nos em Bakhtin (2003, p. 280), entendemos que cada esfera de nossa sociedade elabora seus "tipos relativamente estáveis de enunciados", nomeados pelo autor como gêneros discursivos ${ }^{3}$. Em outras palavras, entendemos, a partir desse conceito, que o agir social humano está intrinsecamente ligado aos gêneros, os quais instrumentalizam a interação humana. Pelo agir social, são constantemente adaptados para o alcance de novos objetivos de comunicação cada vez mais complexos (daí o emprego da palavra relativamente feito por Bakhtin).

Independentemente das teorias que embasam o estudo e didatização dos gêneros, torna-se claro como pesquisadores têm-se debruçado sobre o tema no sentido de melhor compreendê-lo e/ou possibilitar sua transposição em processos de ensino e aprendizagem. Conforme Marcuschi aponta:

[...] $O$ estudo dos gêneros textuais não são novos e, no Ocidente, já tem pelo menos vinte e cinco séculos, se considerarmos que sua observação sistemática iniciou-se em Platão. O que hoje se tem é uma nova visão do mesmo tema. Seria gritante ingenuidade histórica imaginar que foi nos últimos decênios do século XX que se descobriu e iniciou os estudos dos gêneros textuais. Portanto, uma dificuldade natural no tratamento desse tema acha-se na abundância e diversidade das fontes e perspectivas de análise. Não é possível realizar aqui um levantamento sequer das perspectivas teóricas atuais (MARCUSCHI, 2008, p. 147).

Ao longo do tempo, a amplitude dos gêneros tornou-se tamanha que isso impossibilita elencá-los. Entretanto, os especialistas da área concordam que os estudos e compreensão dos gêneros inicialmente não possuíam a atual amplitude. De uma maneira mais técnica, o termo gênero era comumente empregado para se referir à tradição ocidental como gêneros literários (MARCUSCHI, 2008).

A partir do momento em que estudiosos compreenderam o gênero como inerentemente ligado à condição social humana, houve também interesse do estudo do tema quanto à sua escolarização. Os gêneros, nesse caso, assumem o caráter de eventos de (multi)letramento (BARROS, 2012) e, nessa perspectiva, o ensino dos gêneros se torna indissociável do letramento escolar.

Conforme advoga Marcuschi (2008), apesar de sua popularização quanto ao ensino de línguas, os estudos de gêneros não estão somente ligados à sua inserção enquanto objetos de ensino na esfera escolar, mas também sobre o próprio

\footnotetext{
${ }^{3}$ Neste estudo não diferenciamos gêneros textuais de gêneros discursivos, embora optemos pela expressão gêneros textuais, por nos filiarmos às pesquisas do Interacionismo Sociodiscursivo (ISD).
} 
funcionamento da sociedade. A partir dessa ruptura, pôde-se expandir os sentidos empregados por Platão quanto aos gêneros literários. A perspectiva bakthiniana tornouse, assim, um norte para estudos posteriores que puderam se aprofundar no tema, perspectiva essa que é uma das bases epistemológicas do Interacionismo Sociodiscursivo (ISD), corrente teórico-metodológica que se volta para o estudo do agir em sociedade medido pela língua/linguagens, na qual nos apoiamos.

\section{BNCC: contextualização e conceitos relevantes para a pesquisa}

A BNCC (BRASIL, 2018) busca o aumento no desempenho dos alunos da Educação Básica e uma maior padronização na elaboração dos currículos e preparação dos alunos. O ponto fundamental proposto pelo documento é estabelecer, por meio das competências priorizadas, uma educação igualitária entre ensino público e privado, dando ao aluno brasileiro oportunidades semelhantes, independentemente da região geográfica e classe social, por isso a ideia de um "currículo mínimo" (BRASIL, 2018).

Quanto ao contexto histórico no qual se insere o documento, para melhor leitura, é necessário compreender que seu surgimento é fomentado pela Constituição Federal, que estabelece a consolidação de "conteúdos mínimos para o ensino fundamental, de maneira a assegurar formação básica comum e respeito aos valores culturais e artísticos, nacionais e regionais" (BRASIL, 1988, Art. 210).

O documento final da BNCC do EF foi homologado pelo Ministério da Educação em dezembro de 2017 e o do Ensino Médio um ano depois, em dezembro de 2018. Entretanto, o processo da sua construção teve início bem antes, com a criação, pelo MEC, de grupos de trabalho formados por variados agentes ligados à educação. Após sua aprovação, a BNCC se tornou um instrumento de referência dos conhecimentos indispensáveis a todos os alunos da Educação Básica, independentemente de sua origem, classe social ou local de estudo. Um documento construído colaborativamente por especialistas de todo o Brasil, gestores, docentes e até uma consulta pública online, cuja missão é de reduzir as desigualdades de aprendizado, estabelecendo as habilidades e competências fundamentais em cada etapa da Educação Básica por meio da obrigatoriedade de seu cumprimento. 
BNCC de Língua Portuguesa: um olhar comparativo entre as fases do Ensino Fundamental e do Ensino Médio

A BNCC pauta-se em dois conceitos importantes: competências e habilidades; as quais o aluno deve desenvolver ao longo de toda a Educação Básica.

[...] competência é definida como a mobilização de conhecimentos (conceitos e procedimentos), habilidades (práticas, cognitivas e socioemocionais), atitudes e valores para resolver demandas complexas da vida cotidiana, do pleno exercício da cidadania e do mundo do trabalho. (BRASIL, 2018, p. 8, grifo nosso).

O conceito de competência visa propiciar ao aluno brasileiro oportunidades semelhantes, independentemente da região geográfica e classe social. $\mathrm{O}$ documento elenca, a priori, dez competências gerais para todas as áreas da Educação Básica que evidenciam, "no âmbito pedagógico, os direitos de aprendizagem e desenvolvimento" (BRASIL, 2018, p. 8).

[...] Ao adotar esse enfoque, a BNCC indica que as decisões pedagógicas devem estar orientadas para o desenvolvimento de competências. Por meio da indicação clara do que os alunos devem "saber" (considerando a constituição de conhecimentos, habilidades, atitudes e valores) e, sobretudo, do que devem "saber fazer" (considerando a mobilização desses conhecimentos, habilidades, atitudes e valores para resolver demandas complexas da vida cotidiana, do pleno exercício da cidadania e do mundo do trabalho), a explicitação das competências oferece referências para 0 fortalecimento de ações que assegurem as aprendizagens essenciais definidas na BNCC (BRASIL, 2018, p. 13).

Outra categoria organizadora do currículo na BNCC são os campos de atuação das práticas de linguagem. Na BNCC esses campos de atuação direcionam as práticas de leitura, produção e análise linguística/semiótica, organizando as competências e habilidades requeridas para tais práticas. Os campos são organizados de acordo com a modalidade de ensino: EF anos iniciais, EF anos finais e EM (cf. Quadro 2). Passemos, agora, para a seção analítica, em que fazemos um cotejamento entre as etapas do EF (anos finais) e EM.

\section{BNCC: EF e EM na Educação Básica, área de Linguagens e componente Língua Portuguesa}

A seguir, apresentamos uma síntese contrativa do plano textual global do documento da BNCC (BRASIL, 2018), por meio dos títulos e subtítulos vinculados às etapas do $\mathrm{EF}$ e EM, no que se refere à área de Linguagens e ao componente Língua 
Portuguesa. É a partir dessa organização que procuramos desenvolver nosso olhar analítico comparativo entre as duas etapas. Para sintetizar o plano global da parte que nos interessa na BNCC, optamos por demonstrá-lo por sua organização tópica, ou seja, pelos títulos e subtítulos das seções. O quadro a seguir mostra tal organização:

Quadro 1 - Plano textual global do texto da BNCC

\begin{tabular}{|c|c|}
\hline Ensino Fundamental & Ensino Médio \\
\hline $\begin{array}{l}\text { O Ensino Fundamental no contexto da } \\
\text { Educação Básica (p. 57-62) }\end{array}$ & $\begin{array}{l}\text { O Ensino Médio no contexto da Educação } \\
\text { Básica (p. 461-468) } \\
\text { A BNCC do Ensino Médio (p. 469-475) } \\
\text { Currículos: BNCC e itinerários (475-479) }\end{array}$ \\
\hline $\begin{array}{l}4.1 \text { A área de Linguagens: } \\
\text { Competências específicas de Linguagens } \\
\text { para o Ensino Fundamental (p. 63-65) }\end{array}$ & $\begin{array}{l}5.1 \text { A área de Linguagens e suas } \\
\text { Tecnologias: Competências específicas de } \\
\text { Linguagens e suas Tecnologias para o } \\
\text { Ensino Médio (p.481-490) } \\
\text { 5.1.1. Linguagens e suas Tecnologias no } \\
\text { Ensino Médio: competências específicas e } \\
\text { habilidades (p. 491-497) }\end{array}$ \\
\hline $\begin{array}{l}\text { 4.1.1. Língua } \\
\text { Competências específicas de Língua } \\
\text { Portuguesa para o Ensino Fundamental } \\
\text { (p. 67-87) }\end{array}$ & 5.1.2 Língua Portuguesa (p.498-504) \\
\hline $\begin{array}{l}\text { 4.1.1.1. Língua Portuguesa no Ensino } \\
\text { Fundamental - Anos Iniciais: } \\
\text { práticas de linguagem, objetos } \\
\text { de conhecimento e habilidades (p.89- } \\
\text { 135) }\end{array}$ & \\
\hline $\begin{array}{l}\text { 4.1.1.2 Língua Portuguesa no Ensino } \\
\text { Fundamental - Anos Finais: práticas de } \\
\text { linguagem, objetos de conhecimento e } \\
\text { habilidades (p.136-191) }\end{array}$ & $\begin{array}{l}\text { 5.1.2.1 Língua Portuguesa no Ensino } \\
\text { Médio: campos de atuação social, } \\
\text { competências específicas e habilidades (p. } \\
\text { 505-531) }\end{array}$ \\
\hline
\end{tabular}

Fonte: Elaborado pelas autoras, com base no texto da BNCC (BRASIL, 2018).

Como vemos pelo Quadro 1, o plano geral do texto da BNCC referente ao componente Língua Portuguesa pode ser dividido em três grandes partes, tanto na etapa do EF como do EM: 1) O EF/EM no contexto da Educação Básica; 2) a área de Linguagens em cada uma das etapas; 3) a Língua Portuguesa em cada uma dessas etapas. Entretanto, é o último tópico que mais nos interessa nesta pesquisa, por isso, é nele que mais dedicamos nossas observações. Destacamos, porém, que, pela extensão do trabalho, privilegiamos, no que se refere ao EF, apenas aos Anos Finais dessa etapa escolar. São esses três eixos gerados pelos dados de nossa pesquisa documental de conteúdo que norteiam as seções analíticas seguintes, a partir das quais buscamos alcançar os nossos objetivos. 


\section{BNCC: EF e EM no contexto da Educação Básica e na área de Linguagens}

Logo na introdução sobre o EM, de um modo geral, enfatiza-se a importância do nível (EM) quanto à inserção dos alunos no mercado de trabalho. Os perfis dos estudantes, por sua vez, são ilustrados pelo documento como plurais, destacando a individualidade de cada um no processo de interação social e, com efeito, de ensino.

Nesse sentido, ao destacar a agência dos alunos, as palavras protagonismo e projeto de vida são utilizadas para enfatizar ainda mais a condição dos indivíduos no EM enquanto interlocutores legítimos do currículo escolar. Nesse sentido, a leitura crítica da realidade no enfrentamento das crises política, social e ambiental parece ser relacionada a esses estudantes que, em um futuro próximo, serão a nova geração de adultos esperançosamente apta a solucionar tais problemas.

Quanto ao tópico EF no contexto da Educação Básica, o texto traz uma perspectiva de ensino que se coloca como uma continuidade da educação Inicial de forma processual. $\mathrm{O}$ aspecto lúdico do nível é enfatizado pelo documento. Entretanto, a BNCC reforça a ideia da importância da construção de conhecimentos socialmente situados e da criticidade, ampliando e contemplando novas práticas que vão para além da escola.

$O$ documento apresenta um contraste quanto ao EF e EM, no que concerne a área da linguagem. O EF volta-se para a construção de conhecimentos socialmente situados, para a compreensão, exploração, análise e utilização de diversas semioses. Nesse sentido, o EF pretende ampliar o repertório de práticas de linguagem dando sequência aos anos iniciais:

[...] Ampliam-se também as experiências para o desenvolvimento da oralidade e dos processos de percepção, compreensão e representação, elementos importantes para a apropriação do sistema de escrita alfabética e de outros sistemas de representação, como os signos matemáticos, os registros artísticos, midiáticos e científicos e as formas de representação do tempo e do espaço (BRASIL, 2018, p. 58).

Enquanto para o EM, no que se refere à área da linguagem, o documento orienta que deve-se focar na ampliação da autonomia, do protagonismo e autoria, levando-se em consideração a apropriação de diferentes gêneros textuais/discursivos, com enfoque maior nos aspectos relacionados à cidadania, agência e mercado de trabalho. Essa ideia 
parece estar em harmonia com a proposta governamental intitulada Ensino Médio Inovador (BRASIL, [2020]), criado pela Portaria no 971, de 9 de outubro de 2009. 0 programa vincula-se às diretrizes e metas do Plano Nacional de Educação 2014-2024 e à reforma do Ensino Médio e é regulamentado pela Resolução do Fundo Nacional de Desenvolvimento da Educação.

$\mathrm{O}$ documento entende que ao longo do $\mathrm{EF}$ deve haver uma progressão de conteúdos, estimulando uma ampliação dos conhecimentos dos alunos. Em suma, essa lógica com base na progressão naturalmente se aplica à progressão para o EM, em que a natureza dos conteúdos é explorada de forma mais complexa.

O texto também apresenta deveres de uma escola que acolhe juventudes, que se baseia em valores como atrelar os conhecimentos construídos aos desafios da realidade, protagonismo e autonomia em questões sociais, profissionais, intelectuais e políticas. 0 tom empregado ao documento explicita um EM mais voltado para o aprofundamento e aplicação de conteúdos apropriados em detrimento do EF que visa construir conteúdos que possam ser expandidos e aprofundados no EM.

No EF as questões voltadas à linguagem devem levar o aluno a compreendê-la de forma dinâmica, socialmente situada e como expressão de diferentes identidades. Assim como no EM, a construção de uma sociedade mais justa e igualitária é trazida na introdução das seções. A ideia de engajamento e criticidade na análise dos mais diversos discursos em constantes relações de poder explícitas ou implícitas nas práticas das diferentes linguagens estão presentes nessa seção do EF e EM.

Embora em consonância quanto às questões sociais, a menção sobre mundo do trabalho aparece no EM, mas não na seção do EF quanto esta etapa discorre sobre o ensino de língua/linguagens. Além disso, conforme veremos na próxima seção a ser analisada, no EF há uma maior ênfase em relação aos recursos utilizados para a produção e compreensão de gêneros textuais, em detrimento das questões sociais que ganham força no EM. Um dos motivos para que haja esse deslocamento pode ser o grau de maturidade dos alunos, bem como suas vivências em contextos mais diversos, sejam eles on-line ou não. Esse aspecto será tratado de maneira mais detalhada na seção a seguir.

\section{BNCC: Língua Portuguesa no EF (anos finais) e EM}


BNCC de Língua Portuguesa: um olhar comparativo entre as fases do Ensino Fundamental e do Ensino Médio

Para iniciar esta seção, trazemos um quadro comparativo entre o tratamento dado à proposição de habilidades específicas a serem desenvolvidas pelos estudantes nas etapas do EF e EM.

Quadro 2 - Comparação entre EF e EM quanto à proposição das habilidades

\begin{tabular}{|c|c|c|c|}
\hline \multicolumn{2}{|c|}{$\begin{array}{c}\text { EF (Anos Finais) } \\
\text { Habilidades e objetos de } \\
\text { conhecimento }\end{array}$} & \multicolumn{2}{|c|}{$\begin{array}{c}\text { EM } \\
\text { Habilidades e Competências }\end{array}$} \\
\hline $\begin{array}{l}\text { Campos de } \\
\text { atuação } \\
\text { (agrupados por } \\
\text { duplas de anos } \\
\text { escolares) }\end{array}$ & $\begin{array}{l}\text { Práticas de } \\
\text { linguagem } \\
\text { (os objetos e } \\
\text { habilidades são } \\
\text { relacionados a } \\
\text { práticas } \\
\text { específicas) }\end{array}$ & $\begin{array}{l}\text { Campos de } \\
\text { atuação } \\
\text { (sem agrupamento } \\
\text { por anos escolares) }\end{array}$ & $\begin{array}{l}\text { Práticas de } \\
\text { linguagem } \\
\text { (não há uma relação } \\
\text { específica entre } \\
\text { práticas e habilidades) }\end{array}$ \\
\hline $\begin{array}{l}\text {-Artístico-literário } \\
\text {-Práticas de } \\
\text { estudo e pesquisa } \\
\text {-Jornalístico- } \\
\text { midiático } \\
\text {-Atuação na vida } \\
\text { pública }\end{array}$ & $\begin{array}{l}\text {-Leitura } \\
\text {-Produção de } \\
\text { textos } \\
\text {-Oralidade } \\
\text {-Análise } \\
\text { linguística/semióti } \\
\text { ca }\end{array}$ & $\begin{array}{l}\text {-Vida pessoal } \\
\text {-Artístico-literário } \\
\text {-Práticas de estudo } \\
\text { e pesquisa } \\
\text {-Jornalístico- } \\
\text { midiático } \\
\text {-Atuação na vida } \\
\text { pública }\end{array}$ & $\begin{array}{l}\text {-Leitura } \\
\text {-Escuta } \\
\text {-Produção de textos } \\
\text { (orais, escritos, } \\
\text { multissemióticos) } \\
\text {-Análise linguística/ } \\
\text { Semiótica }\end{array}$ \\
\hline
\end{tabular}

Fonte: Elaborado pelas autoras, com base na BNCC (BRASIL, 2018).

Analisando o Quadro 2, percebemos uma diferença significativa entre as duas etapas: as habilidades e, consequentemente, os gêneros a elas atreladas, estão, no EF, prescritos por duplas de anos escolares (60 e 70 anos e $8^{\circ}$ e $9^{\circ}$ anos), diferentemente do EM que traz as habilidades separadas unicamente pelos campos de atuação. No EF, para cada conjunto de dois anos escolares são prescritas habilidades e objetos de conhecimento específicos para cada um dos campos de atuação e, respectivamente, para cada prática de linguagem (leitura, produção, etc.).

No EM, os quadros das habilidades são direcionados exclusivamente pelos campos de atuação. Diferentemente do EF, o EM também associa cada habilidade a uma respectiva competência da área de Linguagens (seção 5.1.1 da BNCC). Isso indica que o EF vê seus objetos do saber, entre eles, os gêneros, numa concepção de progressão curricular mais tradicional, porquanto eles parecem estar condicionados a certas práticas discursivas e a certas etapas escolares. O EM percorre, por sua vez, uma concepção mais flexível de currículo, uma vez que as habilidades não estão vinculadas a certos objetos do saber ou a práticas específicas (leitura, produção, etc.), mas apenas a competências gerais relacionadas à área de Linguagens. Nesse sentido, entendemos que, embora não 
desconsidere recursos de produção e compreensão dos gêneros, parece que o EM direciona o ensino dos gêneros às complexidades socioculturais.

Um ponto a destacar é que, no EF, os objetos do conhecimento ora são representados por gêneros, ora por recursos linguísticos, ora por estratégias de leitura/produção, entre outros; ou seja, não se define com nitidez, o que se entende por objetos (finalidade da aprendizagem). Como objetos do conhecimento são elencados, por exemplo: Revisão/edição de texto informativo e opinativo (procedimento); Produção de textos jornalísticos orais (prática de linguagem); Construção composicional (elemento da textualidade); Usar adequadamente ferramentas de apoio a apresentações orais (modo adequado de uso de tecnologias); Gêneros de divulgação científica (constelação de gêneros); Variação linguística (conceito linguístico); Conversação espontânea (gênero); Sintaxe (aspecto de funcionamento da língua).

Talvez seja por essa dificuldade de se delimitar quais são os objetos de aprendizagem da Língua Portuguesa que o EM optou por não associar as habilidades aos objetos. Isso por que a própria habilidade já destaca esse objeto, como podemos ver, por exemplo, na habilidade EM13LP19 prescrita para o campo da vida pessoal do EM: "Apresentar-se por meio de textos multimodais diversos (perfis variados, gifs biográficos, biodata, currículo web, videocurrículo, etc.) e de ferramentas digitais (ferramenta de gif, wiki, site, etc.), para falar de si mesmo de formas variadas, considerando diferentes situações e objetivos" (BRASIL, 2018, p. 511).

Aqui é possível depreender que a habilidade EM13LP19, trazida como exemplo, tem respaldo em objetos como: domínio de textos multimodais; de gêneros diversos, como, gifs biográficos, biodata, currículo web; adequação a diferentes situações discursivas e o domínio da oralidade para falar de si mesmo. Essa habilidade está relacionada, pelo documento, à competência específica 3: "Utilizar diferentes linguagens (artísticas, corporais e verbais) para exercer, com autonomia e colaboração, protagonismo e autoria na vida pessoal e coletiva, de forma crítica, criativa, ética e solidária, defendendo pontos de vista que respeitem o outro e promovam os Direitos Humanos, a consciência socioambiental e o consumo responsável, em âmbito local, regional e global" (BRASIL, 2018, p. 493). Como vemos, o EM mostra-se, assim, mais centrado no desenvolvimento de competências globais do que com no domínio de objetos linguístico-discursivos. 
BNCC de Língua Portuguesa: um olhar comparativo entre as fases do Ensino Fundamental e do Ensino Médio

No que tange à progressão dos conhecimentos em relação ao EF, a BNCC do EM leva em conta:

- A consolidação do domínio de gêneros do discurso/gêneros textuais já contemplados anteriormente e a ampliação do repertório de gêneros, sobretudo dos que supõem um grau maior de análise, síntese e reflexão. - $\quad O$ aumento da complexidade dos textos lidos e produzidos em termos de temática, estruturação sintática, vocabulário, recursos estilísticos, orquestração de vozes e semioses.

- $\quad$ foco maior nas habilidades envolvidas na reflexão sobre textos e práticas (análise, avaliação, apreciação ética, estética e política, valoração, validação crítica, demonstração etc.), já que as habilidades requeridas por processos de recuperação de informação (identificação, reconhecimento, organização) e por processos de compreensão (comparação, distinção, estabelecimento de relações e inferência) já foram desenvolvidas no Ensino Fundamental (BRASIL, 2018, p. 499, grifo nosso).

No EM, o movimento de ampliar conhecimentos sócio-históricos de forma proporcional é realizado pelo exercício da criticidade que parece dar continuidade ao trabalho realizado no EF. É no EM, por exemplo, que os alunos teriam contato maior com a literatura juvenil e periférico-marginal, o culto, o clássico, trazendo maiores possibilidades de apreciação, em processos complexos que exigem adaptações, remediações. Quanto aos gêneros da esfera jornalístico-midiática, há a menção de gêneros como advergame, unboxing, entre outros gêneros perpassados pela narrativa mercadológica que passam despercebidos na Web 2.0 como uma simples forma de entretenimento.

Enquanto no EF, o mesmo campo faz menção aos gêneros. Assim sendo, o EF nos parece estar mais preocupado em levar o aluno a se apropriar dos gêneros de maneira menos complexa quanto a seus recursos linguísticos, sem um enfoque tão amplo no engajamento social, uma vez que o próprio documento destaca que tais práticas ficam a cargo do EM. Corroborando com a ideia de progressão ao longo do EF, a BNCC entende que

[...] Ao chegar ao Ensino Médio, os estudantes já têm condições de participar de forma significativa de diversas práticas sociais que envolvem a linguagem, pois, além de dominarem certos gêneros textuais/discursivos que circulam nos diferentes campos de atuação social considerados no Ensino Fundamental, eles desenvolveram várias habilidades relativas aos usos das linguagens. Cabe ao Ensino Médio aprofundar a análise sobre as linguagens e seus funcionamentos [...] 
(BRASIL, 2018, p. 498).

No EM, o gênero e seus aspectos linguísticos/semióticos, discursivos, enunciativos, sua funcionalidade, contexto, práticas de uso, etc. aparecem, mas não como finalidade, e sim como meio de se desenvolver habilidades e competências.

Tanto o EF como o EM abordam gêneros relacionados ao letramento mais tradicional da escrita e da esfera analógica, assim como gêneros emergentes da esfera digital, estando, assim, em consonância com estudos recentes sobre novos multiletramentos (ROJO, 2017), que hoje tentam dar conta da complexidade das novas e múltiplas formas de linguagens e semioses que emergem no campo digital e sua articulação com o letramento da escrita. No Quadro 3, é possível verificar que os campos de atuação abordados pelo EF e EM assemelham-se nas três etapas da escolaridade, mas diferem-se em alguns aspectos.

Quadro 3 - Comparativo entre campos de atuação do EF e EM

\begin{tabular}{|l|l|l|}
\hline \multicolumn{2}{|c|}{ ENSINO FUNDAMENTAL } & \multicolumn{1}{c|}{ ENSINO MÉDIO } \\
\multicolumn{1}{|c|}{ Anos Iniciais } & \multicolumn{1}{c|}{ Anos Finais } & \\
\hline $\begin{array}{l}\text { Campo da vida } \\
\text { cotidiana }\end{array}$ & Campo da vida pessoal \\
\hline $\begin{array}{l}\text { Campo artístico- } \\
\text { literário }\end{array}$ & $\begin{array}{l}\text { Campo artístico- } \\
\text { literário }\end{array}$ & Campo artístico-literário \\
\hline $\begin{array}{l}\text { Campo das } \\
\text { práticas de estudo } \\
\text { e pesquisa }\end{array}$ & $\begin{array}{l}\text { Campo das } \\
\text { práticas de estudo } \\
\text { e pesquisa }\end{array}$ & Campo das práticas de estudo e pesquisa \\
\hline $\begin{array}{l}\text { Campo da vida } \\
\text { pública }\end{array}$ & $\begin{array}{l}\text { Campo } \\
\text { jornalístico- } \\
\text { midiático }\end{array}$ & Campo jornalístico-midiático \\
\cline { 2 - 4 } & $\begin{array}{l}\text { Campo de atuação } \\
\text { na vida pública }\end{array}$ & Campo de atuação na vida pública \\
\hline
\end{tabular}

Fonte: BNCC (BRASIL, 2018, p. 501).

Ao compararmos os Anos Iniciais do EF ao EM, é possível verificar uma diferença já nos primeiros campos de ambos os níveis. Embora os nomes possam apresentar alguma ligeira semelhança em um primeiro momento, seus níveis de complexidade são explicitados na leitura do documento. Conforme o texto coloca:

[...] Os campos de atuação considerados em cada segmento já contemplam um movimento de progressão que parte das práticas mais cotidianas em que a circulação de gêneros orais e menos institucionalizados é maior (Campo da vida cotidiana), em direção a práticas e gêneros mais institucionalizados, com predomínio da escrita e do oral público (demais campos) (BRASIL, 2018, p. 84). 
BNCC de Língua Portuguesa: um olhar comparativo entre as fases do Ensino Fundamental e do Ensino Médio

Com enfoque maior em práticas sociais que demandem conhecimentos sociais, culturais e históricos mais profundos, no EM há forte menção à denúncia de discursos que venham a ferir os Direitos Humanos e à avaliação dos mais plurais argumentos, no sentido de propiciar maior autonomia quanto à produção e análise ideológica dos conteúdos em questão.

De forma mais detalhada, por exemplo, tanto no EF quanto no EM, a produção e compreensão dos gêneros do campo jornalístico-midiático é explicitada, mas sem especificar os recursos linguísticos a serem contemplados (como a modalização que aparece entre aspectos a serem trabalhados no $\mathrm{EF}$, por exemplo), uma vez que esses parecem já ter tido maior evidência do ponto de vista da produção e compreensão linguística dentro do EF.

Embora de forma menos aprofundada que o EM, porém a caminho do EM, o EF, em seus anos finais, aprofunda-se no tratamento dos gêneros do campo de atuação na vida pública e do jornalístico-midiático. Os gêneros desses campos são privilegiados a partir de estratégias de produção, compreensão e análise, englobando diferentes semioses. Entretanto, nota-se a diferença no enfoque dado quanto à descrição dos campos proposta pelo documento, já que no EF o campo jornalístico-midiático menciona que:

[...] Para além de construir conhecimentos e desenvolver habilidades envolvidas na escuta, leitura e produção de textos que circulam no campo, o que se pretende é propiciar experiências que permitam desenvolver nos adolescentes e jovens a sensibilidade para que se interessem pelos fatos que acontecem na sua comunidade, na sua cidade e no mundo e afetam as vidas das pessoas, incorporem em suas vidas a prática de escuta, leitura e produção de textos pertencentes a gêneros da esfera jornalística em diferentes fontes, veículos e mídias, e desenvolvam autonomia e pensamento crítico para se situar em relação a interesses e posicionamentos diversos e possam produzir textos noticiosos e opinativos e participar de discussões e debates de forma ética e respeitosa (BRASIL, 2018, p. 140).

O foco na compreensão social cultural e política juntamente com o ensino de elementos linguísticos é visivelmente indicado na etapa do EF. Entretanto, no EM a descrição do campo jornalístico-midiático torna-se ainda mais aprofundada com relação aos aspectos anteriormente mencionados.

[...] No Ensino Médio, enfatiza-se ainda mais a análise dos interesses que 
movem o campo jornalístico-midiático e do significado e das implicações do direito à comunicação e sua vinculação com o direito à informação e à liberdade de imprensa. [...] Além dos gêneros propostos para o Ensino Fundamental, são privilegiados gêneros mais complexos relacionados com a apuração e o relato de fatos e situações (reportagem multimidiática, documentário etc.) e com a opinião (crítica da mídia, ensaio, vlog de opinião etc.). Textos, vídeos e podcasts diversos de apreciação de produções culturais também são propostos, a exemplo do que acontece no Ensino Fundamental, mas com análises mais consistentes, tendo em vista a intensificação da análise crítica do funcionamento das diferentes semioses (BRASIL, 2018, p. 522).

No caso da descrição do campo jornalístico-midiático, o EF traz consigo o objetivo de levar o aluno a ler e produzir textos cujas reflexões possam ir para além do ensino estrutural da língua. A partir das duas descrições acerca do trabalho com o campo jornalístico-midiático (EF) e jornalístico-midiático (EM), é possível depreender que, no EM, as práticas sociais voltam-se a uma análise mais crítica das práticas de linguagem, uma vez que até mesmo o vínculo entre a liberdade de imprensa e democracia é estabelecido no texto. Entre os gêneros mencionados no campo jornalístico-publicitário do EF estão a crônica, a carta ao leitor, meme, vlog noticioso, charge digital, political remix, anúncio publicitário, propagandas, entre outros.

Entretanto, é no EM que aparentemente as novas dinâmicas de interação por meio de gêneros de livre (re)produção em plataformas de alto impacto em que verificar fontes e certificar-se das arbitrariedades presentes nos textos tornam-se mais profundas e vistas como essenciais. Como exemplos de gêneros mencionados para o campo jornalísticomidiático na etapa do EM, além da retomada de gêneros já mencionados no EF (jingle, meme, charge digital), podem ser citados gêneros mais complexos tais como a fotodenúncia, fotorreportagem, reportagem multididática, documentário, vlog de opinião, ensaio, etc.

A complexidade dos gêneros, bem como a análise dos mais diversos discursos que circulam na Web parecem ganhar mais força no EM. A menção de gêneros digitais tanto no EF quanto no EM pode justificar o uso da palavra midiática ao se referir à esfera jornalística. Esse olhar sobre os gêneros e práticas sociais na Internet está diretamente relacionado aos estudos dos novos letramentos, como elucida Rojo (2017).

Seguindo a lógica supracitada, dentro do campo jornalístico-midiático, as esferas publicitárias, legais e normativas também ganham maior destaque na etapa final do EF, não por serem unicamente compostas por gêneros que demandem a construção de novos 
conhecimentos do ponto de vista morfológico ou sintático, por exemplo, mas também por objetivarem pavimentar o caminho para um EM, que busca permitir aos alunos se colocarem contra injustiças, desigualdades por meio da linguagem, como já posto nas discussões de tópicos anteriores.

No EM, a exploração de canais de participação, inclusive digitais, também é prevista, assim como habilidades para os procedimentos de busca e construção coletiva de conhecimento on-line. A criticidade no uso dos gêneros digitais na era das fake news atribui à escola uma nova responsabilidade. Se antes as notícias eram somente lidas nos jornais ou vistas na TV (o que não as torna neutras, claro), hoje temos notícias sendo publicadas a todo instante, por qualquer um que assim desejar. Conforme apontam estudiosos da área (BARROS, 2012; MARCUSCHI, 2008), conhecer o funcionamento social dos gêneros é de suma importância, uma vez que a falta de domínio das formas de mobilização situada dos gêneros pode inviabilizar o engajamento em diferentes práticas sociais e campos de atuação.

\section{Considerações Finais}

Em um movimento que indica progressão, a BNCC do EF evidencia estar mais vinculada a aspectos menos complexos dos gêneros textuais quanto à sua natureza social, política, histórica e cultural. Nesse sentido, O EF parece demonstrar em seu discurso a importância da apropriação de elementos linguísticos e sociais que serão retomados no EM.

De certa forma, esse movimento nos parece compreensível, uma vez que os alunos do EM estão mais maduros, experientes e cognitivamente aptos a analisar de forma mais crítica diferentes temas, bem como as complexidades do discurso nas mais plurais possibilidades de interação. As demandas dos novos letramentos acabam por permear a produção do documento que prevê práticas sociais on-line, que hoje podem, inclusive, nortear novos rumos sociais (como a impossibilidade de identificar notícias falsas, fontes e aspectos que possam identificar arbitrariedade em textos que formam opiniões em larga escala).

Embora tanto o EF quanto o EM se ocupem de questões sociais de uso da(s) linguagem(ns), é possível notar que o EM adota um discurso mais voltado à autonomia 
e inserção de práticas sociais que demandam conhecimentos que exigem um panorama social, político e histórico mais profundo quanto ao uso dos gêneros textuais.

Diante disso, concluímos que há um visível enfoque (em especial no EM) no que se refere às questões relacionadas aos gêneros enquanto artefatos sócio-históricos na era digital. Entendendo que no contexto de produção do documento é tido como crucial uma nova demanda emergente quanto à autonomia e reconhecimento da profusão de notícias falsas, bem como a necessidade de preparar indivíduos para uma era em que conceitos como autoria, fonte e participação se tornaram muito mais complexos.

Um dos objetivos elencados no documento é o do uso crítico e historicamente situado dos gêneros digitais, uma vez que autores como Rojo (2017) apontam a necessidade de a escola se ocupar dessa nova demanda, que para nós se torna cada vez mais crucial, uma vez que a Internet assume hoje um dos papéis mais centrais quanto aos novos rumos sociais. Portanto, além de trazer gêneros mais tradicionais como o anúncio publicitário, o documento também faz menção a gêneros como o meme e vlog noticioso.

Os gêneros contemplados no EF são consolidados no EM que, por sua vez, os exploram em maior profundidade. $O$ repertório das práticas sociais também é expandido no $\mathrm{EM}$, em comparação com o $\mathrm{EF}$, assim como a complexidade dos textos em aspectos sintáticos, de vocabulário e semioses, para citar alguns. No EM, conhecimentos de natureza sócio-histórica incitam o exercício da ética, criticidade e apreciação estética. Desse modo, o EF parece pavimentar o caminho para o EM que, no que the concerne, visa formar indivíduos mais autônomos, críticos e reflexivos, especialmente, quanto às práticas digitais na era da pós-verdade.

\section{Referências}

BAKHTIN, Mikhtin. Gêneros do discurso. In: BAKHTIN, Mikhtin. Estética da criação verbal. Tradução Paulo Bezerra. 4. ed. São Paulo: Martins Fontes, 2003. p. 261-306.

BARROS, Eliana Merlin Deganutti de. Gêneros textuais e práticas de letramento: a temporalidade verbal no gênero crítica cinematográfica. Revista Brasileira de Linguística Aplicada, Belo Horizonte, v. 9, n. 1, p. 177-200, 2009.

BARROS, Eliana Merlin Deganutti de. Gestos de ensinar e de aprender gêneros textuais: a sequência didática como instrumento de mediação. 2012. 359 f. Tese (Doutorado em Estudos da Linguagem) - Universidade Estadual de Londrina, Londrina, 2012. 
BNCC de Língua Portuguesa: um olhar comparativo entre as fases do Ensino Fundamental e do Ensino Médio

BRASIL. Ministério da Educação. Base nacional comum curricular. Brasília, DF: MEC, 2018. Disponível em: http://basenacionalcomum.mec.gov.br/wp-

content/uploads/2018/11/7._Orienta\%C3\%A7\%C3\%B5es_aos_Conselhos.pdf. Acesso em: 20 maio 2018.

BRASIL. Ministério da Educação. Ensino médio inovador. Brasília, DF: MEC, [2020]. Disponível em: http://portal.mec.gov.br/component/content/article?id=13439:ensinomedio-inovador. Acesso em: 16 jul. 2020.

BRASIL. Ministério da Educação. Parâmetros curriculares nacionais: Língua Portuguesa. Brasília, DF: Secretaria de Educação Fundamental, 1998.

GIL, Antonio Carlos. Métodos e técnicas de pesquisa social. 6. ed. São Paulo: Atlas, 2014.

MARCUSCHI, Luiz Antônio. Produção textual: análise de gêneros e compreensão. São Paulo: Parábola Editorial, 2008.

ROJO, Roxane. Novos multiletramentos e protótipos de ensino: por um Web-Currículo. In: CORDEIRO, Glais Sales; BARROS, Eliana Merlin Deganutti de; GONÇALVES, Adair Vieira (org.). Letramentos, objetos e instrumentos de ensino: Gêneros textuais, sequências e gestos didáticos. Campinas, SP: Pontes, 2017. p. 189-216.

Submetido: 24 set. 2020 Aceito: 21 jul. 2021 